\title{
The Role of Free Radicals and p53 in Neuron Apoptosis in vivo
}

\author{
Katherine A. Wood and Richard J. Youle \\ Biochemistry Section, Surgical Neurology Branch, National Institutes of Health, Bethesda, Maryland 20892-1414
}

\begin{abstract}
Apoptosis is a mechanism of cell death operative in the normal development and regulation of vertebrate tissues and organ cellularity. During the postnatal development of the mouse cerebellum, extensive granule neuron apoptosis occurs that may regulate the final granule cell to Purkinje cell stoichiometry observed in the adult. Cerebellar granule cells are highly sensitive to genotoxic agents such as gamma-irradiation and methylazoxymethanol during the first 2 weeks of postnatal development. We demonstrate that ionizing radiation induces extensive cerebellar granule cell death via apoptosis in vivo. In p53 null mice, however, the cerebellar granule cells do not undergo apoptosis in response to gamma-irradiation. In mice heterozygous for the p53 allele, the granule cells apoptosis is delayed, indicating an intermediate response. The developmental apoptosis of cerebellar granule cells, however, occurs similarly in wild-type and p53 null mice. Therefore, neurons undergo p53-dependent and p53-independent apoptosis, depending upon the initiating stimulus that triggers DNA fragmentation. In contrast to $x$-ray damage, the extensive death of cerebellar granule cells induced by methylazoxymethanol was found to be independent of the DNA fragmentation characteristic of apoptosis, and was also independent of expression of p53. Ablation of neuron progenitor cells with genotoxic agents may occur by p53-dependent apoptosis or by p53-independent mechanisms not associated with DNA fragmentation.
\end{abstract}

[Key words: cerebellum, x-irradiation, methylazoxymethanol, apoptosis, p53, free radicals]

The cerebellum processes output of the cerebrum to allow fine coordination of intention to movement. The cerebellar granule cells are the most abundant neuronal cell type of the CNS and function to inhibit the cerebellar Purkinje cell, which provide the sole output of the cerebellar cortex (Ito, 1984). The Purkinje cell to granule cell ratio is tightly regulated, yet the actual stoichiometric ratio varies considerably among species (Lange, 1975). The molecular basis of the cellular development coordinating these two neuronal populations remains unclear, although regulation of granule cell apoptosis may be involved (Wood et al., 1993).

Much of the cerebellar development occurs postnatally. At birth, the cerebellum is covered with a proliferating layer of

\footnotetext{
Received Sept. 20, 1994; revised March 9, 1995; accepted April 19, 1995. We thank Mrs. Patricia Johnson and Mr. Jamal Warner for technical assistance and Mr. John IIarrington for animal care.

Correspondence should be addressed to Dr. Katherine A. Wood, Biochemistry Section, Surgical Neurology Branch, National Institutes of Health, Building 10, Room 5D37, 10 Centre Drive, Bethesda, MD 20892-1414.

Copyright $(1995$ Society for Neuroscience 0270-6474/95/155851-07\$05.00/0
}

granule cell precursors that form the external granular layer (EGL). The granule cells migrate from the EGL during the first 2 to 3 postnatal weeks to form the internal granular layer (IGL), crossing a monolayer of postmitotic Purkinje cells with which the granule cells make synapses. An outer molecular layer forms, comprised of axuns, dendrites, and stellate and basket neurons. Granule cells in the EGL sprout axons that grow into the molecular layer as parallel fibers and synapse to the developing dendrites of the Purkinje cells during the second postnatal week (Ito, 1984). Input from mossy fibers of the deep cerebellar nuclei to the granule cell layer begins by postnatal day 5 and is established by postnatal day 12 . The fastest growth of the cerebellum occurs during the first postnatal week, and by postnatal day 10 , the foliation pattern of the cerebellum is established. The mechanism for the origination of folia remains unknown, but it has been shown that the proliferation rate of granule cells is highest in the EGL in the fissures, which may explain the faster growth observed of the cerebellar fissures than of the superficial gyri (Mares and Lodin, 1970).

Apoptosis has been shown to be a mechanism of physiologic cell death in cerebellar granule neurons in vivo during the first 2 weeks of postnatal development (Wood et al., 1993). At later times in development, granule cell death occurs independently of DNA fragmentation, characteristic of apoptosis. In vitro, granule cells undergo apoptosis with increasing time in culture and in response to a wide variety of agents including 1-methyl4-phenylpyridinium (Dipasquale et al., 1991) and low potassium (D’Mello et al., 1993; Yan et al., 1994).

Germinal cerebellar granule cells are highly sensitive to gamma-irradiation and methylazoxymethanol (MAM), and these DNA modifying agents have been used extensively to alter normal development (Altman and Anderson, 1972; Jones et al., 1972; Inouye and Kameyama, 1983). Iight and electron microscopic studies have indicated that the dying cells observed in the EGL of the rat cerebellum and hippocampus following lowdose irradiation exhibit the morphological characteristics of apoptosis (Inouye et al., 1992; Ferrer et al., 1993). In mice, the effects of MAM induce differential effects, depending upon the day of injection (Bejar et al., 1985). The most dramatic effect on cerebellar cytoarchitecture is observed following MAM treatment on the first 2 postnatal days, resulting in a granule cell deficient cerebellum. Cellular necrosis and nuclear and cytoplasmic changes are noted in the EGL within $48 \mathrm{hr}$ following MAM administration, and by $5 \mathrm{~d}$ after treatment the necrotic debris has been cleared (Jones et al., 1972). Treatment with MAM at a later time point after birth does not alter overall cytoarchitecture, and causes only partial loss of granule cells and the additional presence of an ectopic granule cell layer (GarciaLadona et al., 1991).

Expression of the tumor suppressor gene $p 53$ is upregulated 
Figure 1. Effect of gamma-irradiation on the cerebellar EGL of wild-type and p53 null mice. Wild-type mice ( $A$ $F$ ) and p53 null mice $(G-L)$ at $7 \mathrm{~d}$ of age were exposed to a total body dose of 420 rads and sacrificed at different times after irradiation. Frozen midsagittal sections were prepared from the cerebellum of littermate controls $(A, D$, $G$, and $J)$ and at $7(B, E, H$, and $K)$ and $24 \mathrm{hr}(C, F, I$, and $L)$ after irradiation. The specimens were fixed and stained with hematoxylin $(A-C$ and $G-I)$, or analyzed for DNA fragmentation $(D-F$ and $J-L$ ) utilizing the unmodified form of T7 DNA polymerase as described in Materials and Methods. The cerebellar primary fissure is shown.

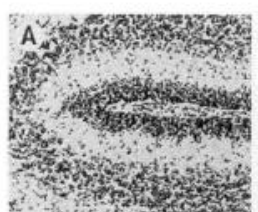

D
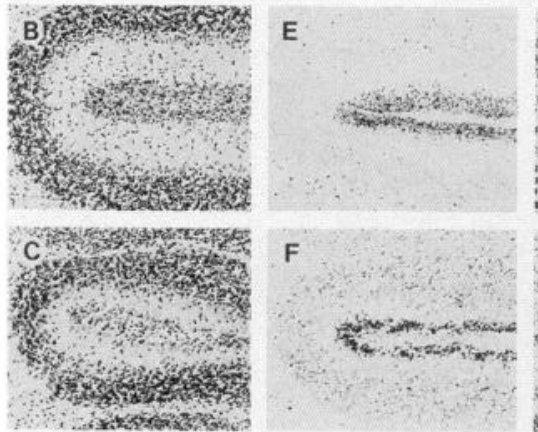

$F$
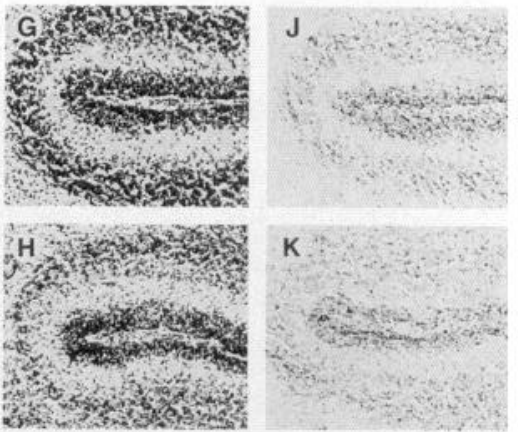

$\mathrm{K}$

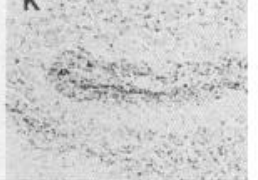

$\mathrm{L}$
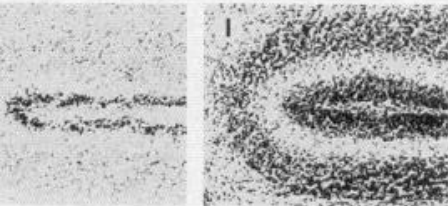

W.t.

$\mu l$ unmodified T7 DNA polymerase and incubated for $30 \mathrm{~min}$. The enzyme was inactivated by the addition of EDTA, pH 8.0 , to $5 \mathrm{~mm}$. The slides were washed in PBS then incubated in $10 \mu \mathrm{g} / \mathrm{ml}$ peroxidasecoupled streptavidin (Kirkegaard and Perry, MD) in PBS for $30 \mathrm{~min}$ in the dark. After washing in PBS, the slides were developed by immersion in freshly prepared $0.125 \mathrm{mg} / \mathrm{ml} 3,3^{\prime}$-diaminobenzidine tetrahydrochloride (Fluka, NY), $15 \mathrm{mg} / \mathrm{ml}$ nickel ammonium sulfate in $0.1 \mathrm{M}$ sodium acetate, $\mathrm{pH} 6$, and $0.001 \%$ hydrogen peroxide. Adjacent sections were fixed as described then stained with hematoxylin. Prior to viewing, the specimens were dehydrated through increasing alcohol series, clarified in xylene, and coverslips were mounted.

Immunohistochemistry. Frozen sections at $20 \mu \mathrm{m}$ were prepared from the cerebella of 6-week-old wild-type and p53 null mice. After air drying at room temperature for $24 \mathrm{hr}$, the sections were washed in PBS then fixed for $10 \mathrm{~min}$ in $4 \%$ formaldehyde in PBS. Immunohistochemistry was performed using the Vectastain $\mathrm{ABC}$ kit (Vector Laboratories, $\mathrm{CA}$ ) according to the manufacturers instructions with $20 \mu \mathrm{g} / \mathrm{ml}$ antip53 antibodies Ab-1 (Oncogene Science Inc., NY) as the primary antibody. Specimens were prepared for viewing as described above.

DNA extraction and electrophoresis. Genomic DNA was extracted from the cerebellar lobes from control animals and at $7 \mathrm{hr}$ following gamma-irradiation in agarose plugs as previously described (Wood et al., 1993). Individual plugs were placed in the wells of a $1 \%$ agarose gel in $1 \times$ TBE buffer and the wells were sealed with $1 \%$ agarose. The gel was electrophoresed in $1 \times$ TBE buffer at $50 \mathrm{~V}$ for $2 \mathrm{hr}$. The gel was stained in $0.5 \mu \mathrm{g} / \mathrm{ml}$ ethidium bromide in water and photographed under ultraviolet light.

\section{Results}

Significant loss of granule cells from the EGL occurs in response to gamma-irradiation (Altman and Anderson, 1972). Figure $1 A$ illustrates the normal complement of granule cells in the EGL in the primary fissure at postnatal day 7 in a midsagittal section. At 7 and $24 \mathrm{hr}$ after a single total-body dose of 420 rads the $\mathrm{EGL}$ is progressively reduced in cell density (Fig. $1 B, C$, respectively). We analyzed adjacent sections for the DNA fragmentation characteristic of apoptosis in granule cells. Figure $1 D$ illustrates the normal spontaneous apoptosis that occurs at postnatal day 7 (Wood et al., 1993). At 7 (Fig. 1E) and 24 hr (Fig. 1F) following $\mathrm{x}$-rays, the majority of the remaining cells in the EGL are labeled for DNA fragmentation. The outer sheets of cells in the EGL are the most rapidly dividing cells and have been called the proliferating zone, whereas the inner sheets of cells are less mitotic and have been called the premigratory zone (Altman, 1972; Kuhar et al., 1993). Although one may have expected the outer proliferating zone to be more susceptible to $\mathrm{x}$-ray-induced apoptosis, we can detect no difference in sensitivity to radiationinduced apoptosis between the two zones. However, there is no 

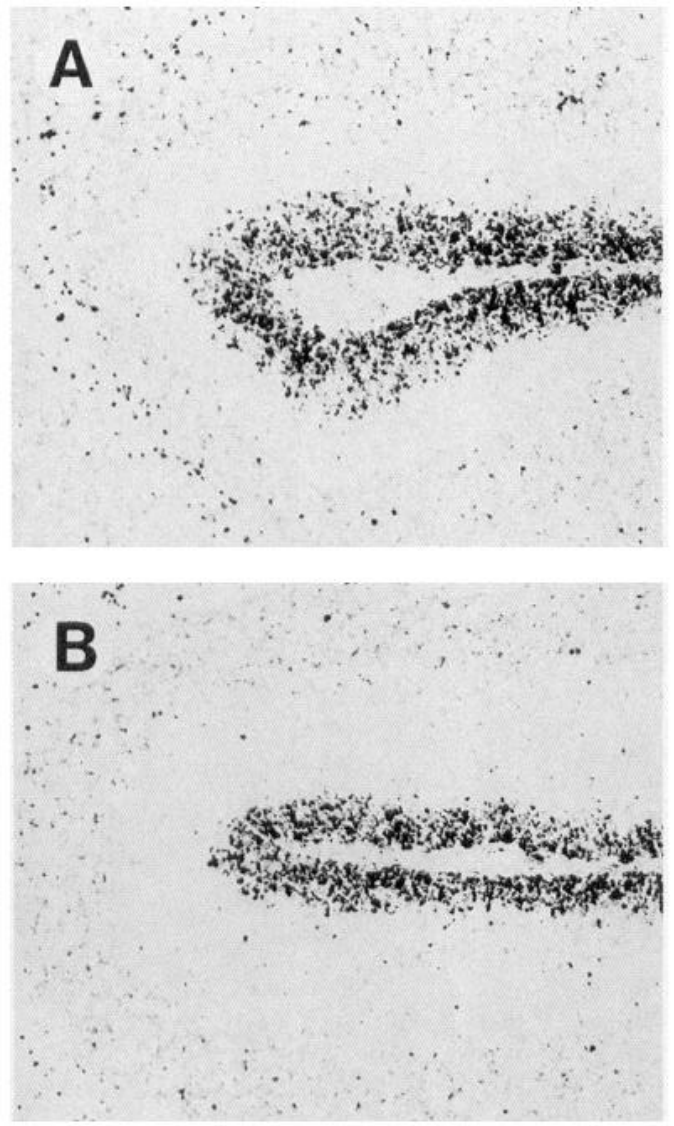

Figure 2. Effect of gamma-irradiation on cerebellum of mice heterozygous for functional p53 allele. Mice heterozygous for functional p53 allele were exposed to a total body dose of 420 rads and sacrificed at $7(A)$ and $24 \mathrm{hr}(B)$ after irradiation. Frozen midsagittal sections were fixed and analyzed for DNA fragmentation utilizing the unmodified form of T7 DNA polymerase as described in Materials and Methods. The cerebellar primary fissure is shown.

apparent induction of apoptosis of cells in the molecular layer or in the IGL by x-rays, and there even appears to be a reduction in the number of cells labeled for DNA fragmentation in internal granular cells at $7 \mathrm{hr}$ post-x-ray treatment compared to the untreated control. Since cells are rapidly migrating from the external to internal granule layers, the decreased physiological apoptosis may mean that the cells normally undergoing apoptosis in the IGL are those most recently migrated into this layer. The
X-rays may have blocked the inward migration by dramatically decreasing the population of external granule cells and thus decreased the population of new migrants prone for apoptosis. Alternatively, x-rays may cause a cell cycle block of internal granule cells that actually inhibits the induction of physiologic cell death.

Transgenic mice that were null for functional $\mathrm{p} 53$ protein were examined for physiologic and $\mathrm{x}$-ray-induced apoptosis. Figure $1 J$ shows the p53-/- cerebellum incubated with T7 DNA polymerase to label cells for DNA fragmentation. Apoptosis occurs similarly to that in wild-type mice (Fig. $1 D$ ), indicating that p53 plays no essential role in this form of physiological neuronal death. Consistent with this result, we have detected no difference in the cytoarchitecture of the cerebellum comparing wild-type mice with p53 null mice. Figure $1, H$ and $I$, shows the complement of cells in the EGL 7 and $24 \mathrm{hr}$ after x-ray treatment, respectively. No discernible loss of granule cells can be found following $\mathrm{x}$-irradiation by hematoxylin staining. Analysis of adjacent sections for DNA fragmentation shows that there is no apparent increase in the number of cells undergoing apoptosis in p53 null mice at 7 (Fig. $1 K$ ) or $24 \mathrm{hr}$ (Fig. $1 L$ ) after gammairradiation. Similarly, the reduction in the numbers of cells in the IGL undergoing spontaneous apoptosis seen in the irradiated wild-type mice was not observed.

Figure 2 shows the labeling for DNA fragmentation at 7 (Fig. $2 A$ ) and 24 (Fig. 2B) after $\mathrm{x}$-rays in the cerebellum of mice heterozygous at the p53 allele. Compared to the wild-type animals (Fig. $1 E, F$ ), there remain higher numbers of cells in the external granular at both 7 and $24 \mathrm{hr}$, and the EGL is not significantly reduced in cellularity. However, the number of cells with fragmented DNA is extensive, suggesting that either clearance of the apoptotic cells is slowed, the time course of initiation of DNA fragmentation to cell clearance is extended, or new cell production through mitosis is able to replenish the loss of granule cells in response to x-rays in mice heterozygous for functional p53 protein.

Figure 3 quantitates the cell loss observed in the EGL in untreated wild-type, p53 heterozygous and p53 null mice and at 7 and $24 \mathrm{hr}$ after irradiation. By $24 \mathrm{hr}$ after irradiation the cell density decreases by approximately $70 \%$ in wild-type animals, whereas a $10 \%$ increase in granule cell density in p53 null animals is found, presumably reflecting the continued proliferation within the granule cell population in the absence of irradiation induced cell death. Heterozygous animals show an intermediate loss in cells in the EGL. The concentration of apoptotic cells

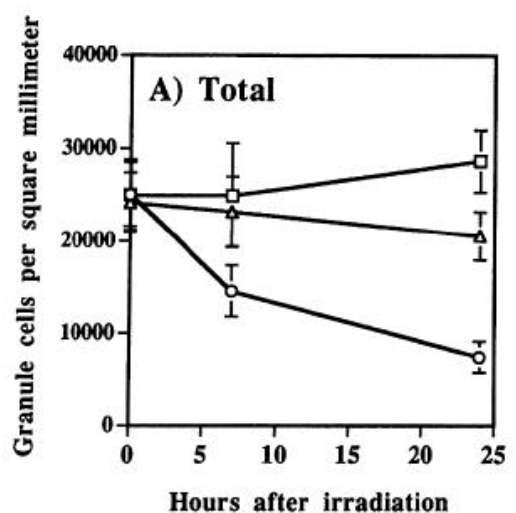

Hours after irradiation

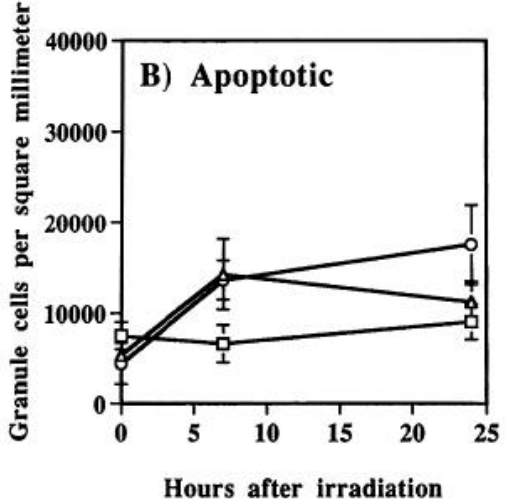

Hours after irradiation
Figure 3. Quantitation of cell loss and apoptosis in the EGL of wild-type, p53 heterozygous, and p53 null mice at 7 and $24 \mathrm{hr}$ after irradiation. Animals were treated and cerebellar sections prepared as described for Figure 1. Cell counts were made in 16 random sections of the EGL on midsagittal cerebellar hematoxylin stained sections for total cell counts $(n=3)$ and on the adjacent section labeled for DNA fragmentation for apoptotic cell number ( $n$ $=3$ ). $A$ shows total counts, and $B$ shows apoptotic cell counts per square millimeter for wild-type (open circles), p53 heterozygous (open triangles), and p53 null mice (open squares) with time after irradiation. 


\section{M $1 \begin{array}{lllll} & 2 & 3 & 4 & M\end{array}$}

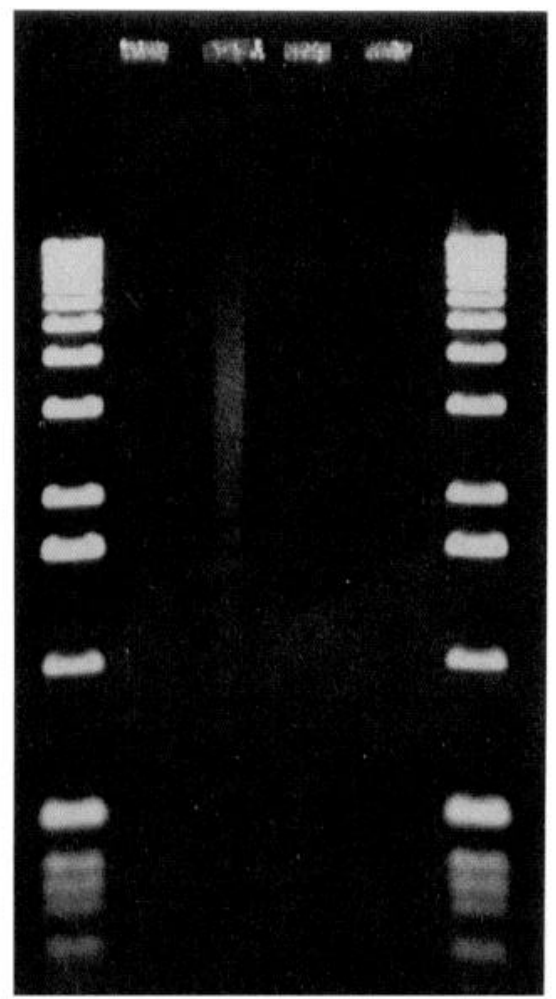

Figure 4. Detection of DNA fragmentation by agarose gel electrophoresis and ethidium bromide staining. Cerebellar cells from wild-type and p53 null 7-d-old control mice and at $7 \mathrm{hr}$ post-x-ray were trapped in agarose. RNA and proteins were enzymatically digested and the DNA was analyzed on $1 \%$ agarose gel as described in Materials and Methods. DNA was visualized by staining with ethidium bromide. Lanes 1 and 2, DNA from unirradiated control mice and at $7 \mathrm{hr}$ post-x-ray, respectively. Lanes 3 and 4, DNA from unirradiated p53 null mice and at 7 hr post-X-ray, respectively.

within the external granule cell layer increases by at least twofold following irradiation in wild-type animals. In p53 null animals, there is no significant increase in the numbers of apoptotic cells. Heterozygous animals exhibit an increase in apoptotic cells similar to wild-type animals up to $7 \mathrm{hr}$ after irradiation, but at $24 \mathrm{hr}$, the number of apoptotic cells is intermediate between the wild-type and p53 null animals.

To confirm the presence of extensive DNA fragmentation detected in situ, genomic DNA from cells of the cerebellum from wild-type and p53 null mice at postnatal day 7 and at $7 \mathrm{hr}$ after gamma-irradiation was extracted and analyzed by agarose gel electrophoresis. Figure 4 shows that a DNA ladder pattern characteristic of the fragmentation of DNA into integer multiples of approximately $200 \mathrm{bp}$ is detected following x-rays in wild-type mice (lane 2). We have previously shown that the more sensitive method of hybridization of a radiolabeled DNA probe is needed to detect the DNA fragmentation associated with the lower numbers of physiologically apoptotic cells in untreated P7 cerebellum (lane 1) (Wood et al., 1993). In p53 null mice, there is no evidence for the characteristic DNA ladder pattern following $\mathrm{x}$-rays (lane 4). Thus, the presence of the DNA ladder in total extracted DNA correlates precisely with the detection of extensive apoptosis in situ in the EGL of the cerebellum.
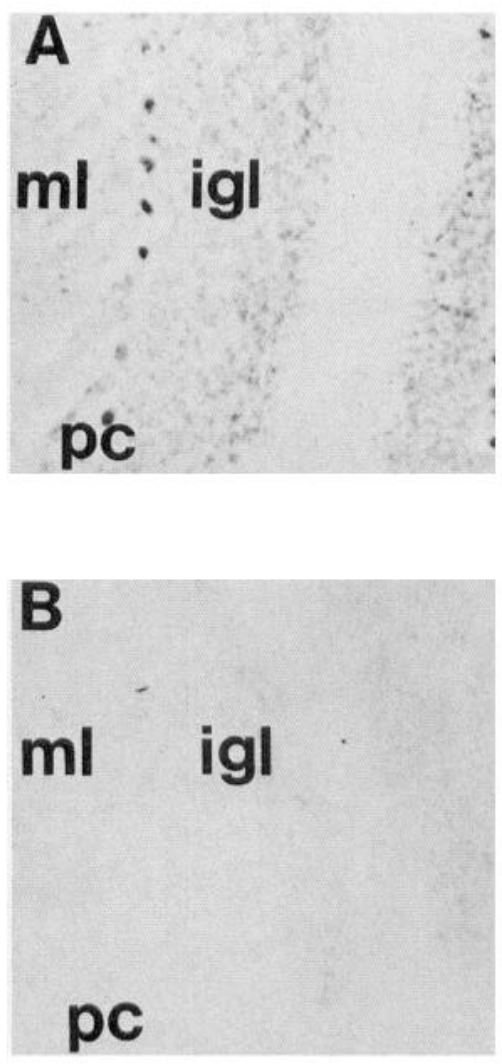

Figure 5. Evidence for expression of p53 in the cerebellar neuronal population. Sagittal sections at $20 \mu \mathrm{m}$ were prepared from the cerebella of 6-week-old wild-type and p53 null mice and stained for p53 protein expression as described in Materials and Methods. A shows the staining for p53 detected in adult wild-type mice, and $B$ shows the lack of staining in adult p53 null mice ( $\mathrm{ml}$, molecular layer; $p c$, Purkinje cell monolayer; $i g l$, internal granular layer).

We examined the expression of p53 protein in neuronal cell types of the adult mouse cerebellum. Figure 5 shows labeling for p53 by immunohistochemistry in wild-type and p53 null mice. In wild-type mice (Fig. $5 A$ ), the most dramatic expression of p53 is seen in the Purkinje cells. The distribution in Purkinje cells is perinuclear and punctate. The IGL is labeled to a lesser extent and the molecular layer shows weak staining only. The lack of labeling in the p53 null mouse confirms the specificity of the antibody staining. It is interesting that postmitotic Purkinje cells express high levels of a tumor suppressor protein that appears to function to block cell replication in the face of DNA damage. This result suggests that p53 plays other roles in neurobiology. It was also of interest that we detected no loss of Purkinje cells in the p53 null mice.

The genotoxic compound MAM has effects on cerebellar development similar to those of x-rays (Altman and Anderson, 1972; Jones et al., 1972). We examined apoptosis in the cerebellum of mice after treatment with MAM. Figure $6 A$, shows the normal architecture of the cerebellum at postnatal day 21 . Figure $6, B$ and $C$, illustrates the dramatic loss of granule cells in wild-type and p53 null mice in response to a single dose of MAM given on the day of birth. At 3 weeks of age the cerebellum is almost completely devoid of a granule cell layer in wild-type and p53 null mice.

We have examined the cerebellum of mice on $1,2,3,4,5$, 8,13 , and $20 \mathrm{~d}$ following MAM treatment on the day of birth. 

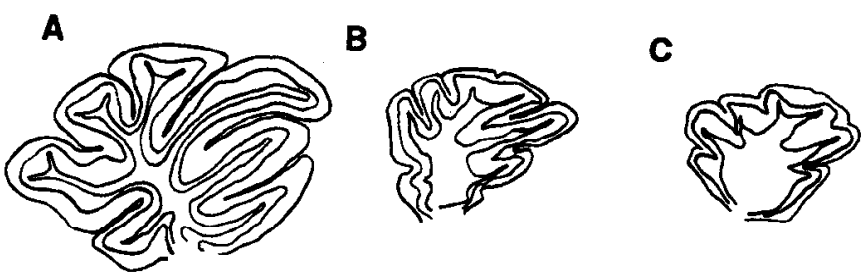

Figure 6. The effect on the cerebellum of a single dose of MAM given on the day of birth. A single dose of MAM was given on the day of birth to wild-type or p53 null mice pups, and the cerebellum was examined at postnatal day 21 by hematoxylin staining of frozen midsagittal sections. $A$ illustrates the size and architecture of a normal mouse brain at postnatal day $21 ; B$ and $C$ show the size and architecture of the cerebellum at postnatal day 21 in wild-type and p53 null mice, respectively, following a single dose of MAM administered on the day of birth.

Table 1 illustrates that MAM causes a granule cell loss of approximately $30 \%$ by postnatal day 3 . The same loss was also seen in p53 null mice, showing that the degree of cell loss was identical regardless of p53 status. Analysis of the cerebellar sections for apoptosis at days 1, 2, 3, 4, and 5 after MAM treatment revealed that the significant cell loss of granule cells in response to MAM did not involve DNA fragmentation characteristic of apoptosis (data not shown). We also analyzed the effect of MAM administration at postnatal day 7 and examined the cerebellum at 1 and $2 \mathrm{~d}$ after treatment. Spontaneous apoptosis was detected on postnatal days 8 and 9, but there was no evidence for an incrcasc in the number of labeled cells in response to MAM (data not shown). Thus, we find no evidence that MAM ablates granule cells by apoptosis, and p53 does not appear to be involved in the cytotoxic mechanism of this genotoxin. Although $\mathrm{x}$-irradiation and MAM cause a similar developmental alteration of the cerebellum, the biochemical pathways of cell death are markedly different.

\section{Discussion}

The $p 53$ tumor suppressor gene has recently been shown to be required for certain inducers of thymocyte apoptosis (Clarke et al., 1993; Lowe et al., 1993a,b) although the role of p53 in physiologic pathways of apoptosis had not been examined. Apoptosis of neuronal precursors in the cerebellum of transgenic mice lacking functional p53 was found to occur similarly to that in wild-type mice. Thus, the physiological pathway of apoptosis in neurons of the EGL occurs by a pathway distinct from that induced in thymocytes by DNA damaging agents, consistent with the overall normal appearance of the cerebellum (Donehower et al., 1992). A recent report has shown that the physiological cell loss in the gut epithelium occurs by a p53-independent apoptotic pathway (Merritt et al., 1994).

We have postulated that apoptosis is one mechanism by which the stoichiometry between granule cells and Purkinje cells is achieved. The spontaneous apoptosis observed in the cerebellum is independent of p53 in both pre- and postmitotic cells. The number of cerebellar granule cells generated is in excess of the adult requirements; therefore, it is likely that the final complement of granule cells is determined in part by the numbers of cells that are rescued from apoptosis, rather than a tightly regulated death-induction mechanism. The process by which granule cells are rescued from death is thus independent of p53 protein levels. Since p53 is required for free radical-induced loss of neurons and lymphocytes but not in physiological loss of
Table 1. Granule cell counts in the EGL on postnatal day 3 in wild-type and p53 null mice after MAM treatment on the day of birth

\begin{tabular}{lll} 
p53 & External granule \\
Genotype & Treatment on day 0 & cells $/ \mathrm{mm}^{2}$ on day $3^{a}$ \\
\hline$+/+$ & Saline & $25,866 \pm 1200$ \\
$+/+$ & Methylazoxymethanol & $18,667 \pm 1155$ \\
$-/-$ & Saline & $24,533 \pm 6110$ \\
$-I-$ & Methylazoxymethanol & $19,067 \pm 2013$
\end{tabular}

"Mice were given a single injection of $5 \mu \mathrm{l} / \mathrm{g}$ of a $1-100$ dilution of MAM in saline, or saline alone, on the day of birth. On postnatal day $3,20 \mu \mathrm{m}$ sagittal sections were prepared as described in Materials and Methods. Cell counts were made in 16 random sections of the EGL on hematoxylin-stained sections ( $n=$ 3). The width of the EGL was the same comparing untreated wild-type and p53 mice or comparing wild-type and p53 null mice following methylazoxymethanol treatment.

neurons, we suggest that free radicals are not a mediator of physiological apoptosis in cerebellar granule cells.

It has been previously demonstrated that levels of the p53 protein increase transiently in mammalian cells after exposure to gamma irradiation. The induction of $\mathrm{p} 53$ is associated with a transient block in cell cycle progression due to arrest at both G1 and $\mathrm{G} 2$ of the cell cycle (Kastan et al., 1992). Cells lacking functional p53 lose the ability to check cell cycle progression at G1 (Kastan et al., 1991) although the pathway downstream of this event may vary between cell types (Kemp et al., 1993). It is postulated that p53 functions to suppress proliferation while the cell attempts repair of DNA damage. DNA damage in excess of repair capacity may trigger a p53-mediated apoptotic death pathway in lymphocytes and thymocytes (Clarke et al., 1993; Lowe et al., 1993a,3b).

$\mathrm{X}$-Rays and MAM have been shown to cause a selective depletion of the external granular cell layer when given shortly after birth. They have been used extensively to alter the final granule cell to Purkinje cell ratio in adult animals and to study the morphogenesis of the cerebellum. We examined the state of the DNA in the cerebellum after exposure of neonatal animals to each of these treatments. The granule cells in the developing cerebellum are especially sensitive to the effects of ionizing radiation as low as 3 rads (Inouye and Kameyama, 1983), although the reason for this unusual sensitivity is unknown. The morphology of the dying cells is indicative of apoptosis (Harmon and Allan, 1988) but to date, biochemical evidence for radiationinduced apoptosis in granule cells in vivo or in vitro has been lacking. We demonstrate here that gamma-irradiation induces extensive DNA fragmentation associated with apoptosis in cerebellar granule cells of the EGL. To examine the role of p53 in neuronal apoptosis we compared granule cell loss and DNA fragmentation in wild-type mice with that in p53 null mice and mice heterozygous for a functional p53 allele. We find that radiation-induced neuron apoptosis is p53 dependent. Mice null for the p53 allele show no increase in the numbers of apoptotic granule cells compared to nonirradiated littermate controls. Mice carrying one copy of the functional allele exhibit an intermediate degree of apoptotic cell death, presumably reflecting a gene dosage effect of p53 on neuronal apoptosis. In wild-type mice, the postmitotic granule cells that have migrated to the developing IGL are resistant to radiation-induced apoplosis. We have previously shown that granule cell loss from the IGL that occurs during development from the third to fifth postnatal week, representing up to $30 \%$ of the initial granule cell population (Landis 
and Sidman, 1978), occurs by a mechanism independent of detectable DNA fragmentation (Wood et al., 1993). Apoptosis therefore appears to be only one mechanism of physiological cell death of granule cells in vivo. The mcchanisms by which granule cells are rescued from apoptosis during development, by the formation of functional synapses with Purkinje cells or by a growth factor, for example, may also increase resistance to ionizing radiation.

We generally see more physiologic apoptosis in the proliferative zone of the EGL than in the premigratory zone of the EGL. However, after X-irradiation we see the entire external granular cell layer undergoes apoptosis similarly. The loss of sensitivity of granule cells to ionizing radiation when these neurons have reached the internal granule layer is not understood. However, many internal granule cells undergo apoptosis normally around postnatal day 7 , apparently after mitosis is complete, and this mechanism is p53 independent.

Ionizing radiation is one of the few inducers of apoptosis for which the initial damaging effects are partially elucidated: direct radiolytic attack on water molccules produces hydroxyl radicals, which leads to oxidative damage to DNA and other cellular macromolecules. It has recently been proposed that the protein $\mathrm{Bcl}-$ 2 , which can block cell death in many in vitro and in vivo systems examined including neurons, can act in an anti-oxidant pathway (Hockenbery et al., 1993). Indeed, the Bcl-2 protein is localized at intracellular sites where endogenous reactive oxygen species are generated (Hockenbery et al., 1991). Free radicals are made during many biochemical reactions including mitochondrial consumption of oxygen, hydrogen peroxide production in peroxisomes, and by nitric oxide synthetase (Richter, 1993). During development, the level of $b c l-2$ mRNA is high in rapidly dividing tissue, including the cerebellum, which may reflect a cellular mechanism to protect against endogenous free radical damage. $\mathrm{Bcl}-2$ expression in the developing cerebellum (Merry et al., 1994) shows an interesting distribution relative to the regions of ccrcbellar granule cells undergoing physiological apoptosis (Wood et al., 1993). At embryonic day 18.5, there is little expression of Bcl-2 in the EGL. We do not detect apoptosis in cerebellar granule cells at postnatal days 1 and 3. In mice, the phase of physiological apoptosis begins around postnatal day 5 and is almost complete by postnatal day 11 (Wood et al., 1993). At P11, the expression of Bcl-2 has increased most notably in the inner, premigratory region of the EGL (Merry et al., 1994). At this time, the most prominent physiologic apoptosis appears to be occurring in the outer, proliferative region of the EGL. Thus, the zones of maximal Bcl-2 expression and apoptosis are mutually exclusive, as if $\mathrm{Bcl}-2$ expression correlates with a lack of apoptosis or vice versa. Perhaps signals from Purkinje cells that rescue the appropriate number of granule cells do so by upregulating the expression of Bcl-2. However, transgenic mice that lack Bcl-2 did not have dramatically different brains arguing against this model, although $\mathrm{Bcl}-2$ homologs such as Bcl-x (Boise et al., 1993) or other apoptosis inhibitors may complement $\mathrm{Bcl}-2$ in the $\mathrm{Bcl}-2$ knockout mice in granule cell salvage.

It is interesting to note the relatively high expression of $\mathrm{p} 53$ detected by immunohistochemistry in the Purkinje cells of the adult cerebellum in wild-type mice. It has recently been shown that in $\mathrm{p} 53$-deficient mice a significant reduction in the cxpression of Bax is found (Miyashita et al., 1994b). Bax is a protein that interacts with Bcl-2 to form heterodimers, which inhibits the death-repressing activity of Bcl-2 (Oltvai et al, 1993). It has also been demonstrated that the $b c l-2$ gene contains a p53 negative response element (Miyashita et al., 1994a). The significance of the levels of Bax in the Purkinje cells is unclear. With the recent discovery of two more proteins that appear to interact with Bcl-2, it seems likely that the loss of one of the molecules involved in the regulation of cell death can be compensated for through alterations in the medley of functionally related proteins.

The role of p53 in both spontaneous and x-ray-induced cell death has bearing upon the tumors of the cerebellum that develop during childhood. These tumors include medulloblastoma and the primitive neuroectodermal tumors (Rorke, 1983) that are believed to be derived from the germinal layers of the floor of the fourth ventricle. Analysis of the various neuroblast markers reveals that these tumor cell types exhibit phenotypes of immature neurons, similar to those expressed by granule cells during maturation. $p 53$ is rarely mutated in these tumors (Saylors et al., 1991; Biegel et al., 1992; Cogen et al., 1992) and the majority of these tumors respond well to $\mathrm{x}$-ray therapy (Slagel et al., 1982). Our results suggest that medulloblastoma cells undergo apoptosis in response to radiation therapy. It is of interest to note, however, that when a $p 53$ mutation has been identified, leading to loss of functional p53, the tumor has been particularly aggressive and refractive to radiation and chemotherapy. It is also significant that recurring tumor tissues show increased frequency of $p 53$ mutation. It can be postulated that radiation and chemotherapy may select for the low numbers of cells that have p53 mutation. In the data presented here we have shown that there appears to be a gene dosage effect. In animals heterozygous for the $p 53$ allele, the response to $x$-rays is delayed compared to the wild-type based upon the frequency of cells with fragmented DNA or upon pyknosis.

We examined whether MAM, which causes direct DNA damage by methylation of guanine residues (Matsumoto and Higa, 1966), would initiate an apoptotic cell death in germinal granule cells. Despite massive cell death, evident from the loss of $30 \%$ of granule cells by $3 \mathrm{~d}$ and culminating in the reduced cerebellar size $21 \mathrm{~d}$ after treatment, MAM did not induce detectable DNA fragmentation in granule cells when administered at either postnatal day 0 or 7. X-irradiation as well as other mitotic inhibitors and DNA alkylating agents cause apoptosis by a p53-dependent pathway in thymocytes (Clarke et al., 1993a,b). Thus, it is somewhat surprising that MAM failed to cause the DNA fragmentation in external granulc cclls indicative of apoptosis. Our results suggest that alternatives of a direct DNA damage mechanism should be considered as the mechanism of MAM toxicity in vivo. Disruption to other macromolecules of the cell may also play an important role in determining the mechanism of cell death.

\section{References}

Altman J (1972) Postnatal development of the cerebellar cortex in the rat. J Comp Neurol 145:353-398.

Altman J, Anderson WJ (1972) Experimental reorganization of the cerebellar cortex. I. Morphological effects of elimination of all microneurons with prolonged X-irradiation started at birth. J Comp Neurol 146:355-406.

Bejar A, Roujansky P, Barry JD, Gombos G (1985) Different effects of methylazoxymethanol on mouse cerebellar development depending on the age of injection. Exp Brain Res 57:279-285.

Biegel JA, Burk CD, Barr FG, Emanuel BS (1992) Evidence for a 17p tumor related locus distinct from p53 in pediatric primitive neuroectodermal tumors. Cancer Res 52:3391-3395.

Boise LH, Gonzalez-Garcia M, Postema CE, Ding L, Turka T, Mao LA, Nunez G, Thompson CB (1993) $b c l-x$, a $b c l$-2-related gene that func- 
tions as a dominant regulator of apoptotic cell death. Cell 74:597608.

Clarke AR, Purdie CA, Harrison DJ, Morris RG, Bird CC, Hooper ML, Wyllie AH (1993) Thymocyte apoptosis induced by p53-dependent and independent pathways. Nature 392:849-851.

Cogen PH, Daneshvar L, Metzger AK, Duyk G, Edwards MSB, Sheffield VC (1992) Involvement of multiple chromosome 17p loci in medulloblastoma tumorigenesis. Am J Hum Genet 50:584-589.

Dipasquale B, Marini AM, Youle RJ (1991) Apoptosis and DNA degradation induced by 1-methyl-4-phenylpyridinium in neurons. Biochem Biophys Res Commun 181:1442-1448.

D'Mello S, Galli C, Ciotti MT, Calissano P (1993) Induction of apoptosis in cercbcllar granule neurons by low potassium: inhibition of death by insulin-like growth factor I and cAMP. Proc Natl Acad Sci USA 90:10989-10993.

Donehower LA, Harvey M, Slagle BL, McArthur MJ, Montgomery J, Butel JS, Bradley A (1992) Mice deficient for p53 are developmentally normal but susceptible to spontaneous tumors. Nature 356:215221.

Ferrer I, Serrano T, Alcantara S, Tortosa A, Graus F (1993) X-rayinduced cell death in the developing hippocampal complex involves neurons and requires protein synthesis. J Neuropathol Exp Neurol 52 370-378.

Garcia-Ladona FJ, Barry JD, Girard C, Gombos G (1991) Ectopic granule cell layer in mouse cerebellum after methyl-azoxy-methanol (MAM) treatment. Exp Brain Res 86:90-96.

Harmon BV, Allan DJ (1988) X-ray-induced death by apoptosis in the immature rat cerebellum. Scan Microscopy 2:561-568.

Hockenbery DM, Zutter M, Hickey W, Nahm M, Korsmeyer SJ (1991) $\mathrm{Bcl}-2$ protein is topographically restricted in tissues characterized by apoptotic cell death. Proc Natl Acad Sci USA 88:6961-6965.

Hockenbery DM, Oltvai ZN, Yin X-M, Milliman CL, Korsmeyer SJ (1993) Bcl-2 functions in an antioxidant pathway to prevent apoptosis. Cell 75:241-251.

Inouye M, Kameyama Y (1983) Cell death in the developing rat cerebellum following $\mathrm{X}$-irradiation of 3 to $100 \mathrm{rad}$ : a quantitative study. J Radiat Res 24:259-269.

Inouye M, Tamarus M, Kameyama Y (1992) Effects of cycloheximide and actinomycin $\mathrm{D}$ on radiation-induced apoptotic cell death in the developing mouse cerebellum. Int J Radiat Biol 61:669-674.

Ito $M$ (1984) The cerebellum and neural control. New York: Raven.

Jones M, Yang M, Mickelsen O (1972) Effects of methazoxymethanol acetate and methylazoxymethanol glucoside on the cerebellum of postnatal Swiss albino mouse. Fed Proc 31:1508-1511.

Kastan MB, Onyekewere O, Sidransky D, Vogelstein B, Harris CC (1991) Participation of p53 protein in the cellular response to DNA damage. Cancer Res 51:6304-6311.

Kastan MB, Zhan Q, El-Deiry WS, Carrier F, Jacks T, Walsh WV, Plunkett BS, Vogelstcin B, Albcrt J. Fornace J (1992) A mammalian cell cycle checkpoint pathway utilizing p53 and GADD45 is defective in Ataxia-Telangiectasia. Cell 71:587-597.

Kemp CJ, Donehower LA, Bradley A, Balmain A (1993) Reduction of $\mathrm{p} 53$ gene dosage does not increase initiation or promotion but enhances malignant progression of chemically induced skin tumors. Cell 74:813-822.

Kuhar SG, Feng L, Vidan S, Ross ME, Hatten ME, Heintz N (1993)
Changing patterns of gene expression define four stages of cerebellar gramule neuron difrerentialion. Development 117:97-104.

Landis DMD, Sidman (1978) Electron microscopic analysis of postnatal histogenesis in the cerebellar cortex of staggerer mutant mice. J Comp Neurol 179.

Lange W (1975) Cell number and cell density in the cerebellar cortex of man and some other mammals. Cell Tissue Res 157:115-124.

Lowe SW, Ruley HE, Jacks T, Housman DE (1993a) p53-dependent apoptosis modulates the cytotoxicity of anticancer agents. Cell 74: 957-967.

Lowe SW, Schmitt EM, Smith SW, Osborne BA, Jacks T (1993b) p53 is required for radiation-induced apoptosis in mouse thymocytes. Nature 362:847 849 .

Mares V, Lodin Z (1970) The cellular kinetics of the developing mouse cerebellum. II. The function of the external granular layer in the process of gyrification. Brain Res 23:343-352.

Matsumoto H, Higa HH (1966) Studies on methylazoxymethanol, the aglycone of cycasin: methylation of nucleic acids in vitro. Biochem J 98:20c-22c.

Merritt AJ, Potten CS, Kemp CJ, Hickman JA, Balmain A, Lane DP, Hall PA (1994) The role of p53 in spontaneous and radiation-induced apoptosis in the gastrointestinal tract of normal and p53-deficient mice. Cancer Res 54:614-617.

Merry DE, Veis DJ, Hickey WF, Korsemeyer SJ (1994) bcl-2 protein expression is widespread in the developing nervous system and retained in the adult PNS. Development 120:301-311.

Miyashita T, Harigai M, Hanada M, Reed JC (1994a) Identification of a p53-dependent negative response element in the $\mathrm{bcl}-2$ gene. Cancer Res 54:3131-3135.

Miyashita T, Krajewski S, Krajewska M, Wang HG, Lin HK, Licbermann DA, Hoffman B, Reed JC (1994b) Tumor suppressor p53 is a regulator of $b c l-2$ and bax gene expression in vitro and in vivo. Oncogene 9:1799-1805.

Oltvai ZN, Milliman CL, Korsmeyer SJ (1993) Bcl-2 heterodimerizes in vivo with a conserved homolog, Bax, that accelerates programed cell death. Cell 74:609-619.

Richter C (1993) Pro-oxidants and mitochondrial $\mathrm{Ca}^{2+}$ : their relationship to apoptosis and oncogenesis. FEBS Lett 325:104-107.

Rorke LB (1983) The cerebellar medulloblastoma and its relationship to primitive neuroectodermal tumors. J Neuropathol Exp Neurol 42: $1-15$.

Sambrook J, Fritsch EF, Maniatis T (1987) Molecular cloning: a laboratory manual. Cold Spring Harbor, NY: Cold Spring Harbor Laboratory.

Saylors RL, Sidransky D, Friedman HS, Bigner SH, Bigner DD, Vogelstein B, Brodeur GM (1991) Infrequent p53 mutations in medulloblastomas. Cancer Res 51:4721-4723.

Slagel DE, Feola J, Houchens DP, Ovejera AA (1982) Combined modality treatment using radiation and/or chemotherapy in an athymic nude mouse-human medulloblastoma and glioblastoma xenograft mode. Cancer Res 42:812-816.

Wood KA, Dipasquale B, Youle RJ (1993) In situ labeling of granule cells for apoptosis-associated DNA fragmentation reveals different mechanisms of cell loss in developing cerebellum. Neuron 11:621632.

Yan G-M, Ni B, Weller M, Wood KA, Paul SM (1994) Depolarization blocks apoptosis of cerebellar neurons. Brain Res 656:43-51. 